\title{
WALK-THROUGH SURVEY REPORT: STYRENE AND NOISE EXPOSURES DURING FIBER REINFORCED PLASTIC BOAT MANUFACTURING
}

at

\section{GRADY-WHITE BOATS, INC. Greenville, NC}

\author{
REPORT WRITTEN BY: \\ Rebecca M. Valladares, E.I.T. \\ Leo M. Blade, C.I.H.
}

REPORT DATE:

September 2005

REPORT NO:

EPHB 306-12a

\author{
U.S. DEPARTMENT OF HEALTH AND HUMAN SERVICES \\ Centers for Disease Control and Prevention \\ National Institute for Occupational Safety and Health \\ Division of Applied Research and Technology \\ Engineering and Physical Hazards Branch \\ 4676 Columbia Parkway, Mail Stop R-5 \\ Cincinnati, Ohio 45226-1998
}


SITE SURVEYED:

SIC CODE:

SURVEY DATE:

SURVEY CONDUCTED BY:

EMPLOYER REPRESENTATIVES CONTACTED:
Grady-White

Greenville, North Carolina

3732 (Boat Manufacturing And Repair)

June 30, 2005

Rebecca M. Valladares, E.I.T. NIOSH, Cincinnati, OH

Leo M. Blade, C.I.H.

NIOSH, Cincinnati, OH

Jim Hardin

Compliance Manager, Grady-White 


\section{DISCLAIMER}

Mention of company names or products does not constitute endorsement by the Centers for Disease Control and Prevention. 


\section{Introduction}

The National Institute for Occupational Safety and Health (NIOSH) is part of the Centers for Disease Control and Prevention (CDC) in the U.S. Department of Health and Human Services (DHHS). NIOSH was established in 1970 by the Occupational Safety and Health (OSH) Act, at the same time that the Occupational Safety and Health Administration (OSHA) was created in the U.S. Department of Labor (DOL). The OSH Act mandated NIOSH to conduct research and education programs separate from the standard-setting and enforcement functions conducted by OSHA. An important area of NIOSH research involves measures for controlling occupational exposures to potential chemical and physical hazards.

On June 30, 2005, researchers from the Engineering and Physical Hazards Branch (EPHB) of the Division of Applied Research and Technology (DART) conducted a walkthrough survey at Grady-White Boats, Inc., in Greenville, North Carolina. The primary purpose of this walk-through was to learn more about the fiberglass-reinforced plastic (FRP) boat manufacturing industry and to assess the suitability of this facility for an indepth survey. The main goals for the walk-through survey included performing a preliminary assessment of the occupational exposures to styrene vapor in air and observing the effectiveness of engineering exposure-control measures during the FRP boat manufacturing operations. A secondary objective was to perform a preliminary assessment of the noise exposures occurring during these operations.

The FRP boat manufacturing process mainly used at Grady-White is known as the open molding process. Cold-press pneumatic molding (a form of closed molding) is used to fabricate small hatch covers. The facility has $350,000 \mathrm{ft}^{2}$ of floor area and employs 360 to 470 people depending on demand. This is the only facility that manufactures GradyWhite brand boats. The boat size range is from 18 to 36 feet (ft.) in length. The facility operates one shift per day beginning at 7:00 AM. There are approximately 1700-2000 boats made per year including many different models. Most models sell from 50 to 200 boats per year.

\section{Styrene Usage and the Hazards of Exposure to Styrene and Noise}

The major chemical component of concern in terms of occupational exposures in the FRP process is styrene. Styrene is a fugitive emission, a result evaporating from resins, gel coats, solvents, and surface coatings used in the manufacturing process. The thermo set polyester resin used at this plant is Maximum Achievable Control Technology (MACT) compliant and contains 33 to 34 percent styrene by weight. Styrene is an essential reactive diluent for polyesters because it reduces the viscosity of the polyester mixture making it thinner and more capable of coating fiber reinforcements allowing the reactive sites on the molecules to interact. As an active diluent, styrene will react in the freeradical cross-linking reaction. Cross-linking is the attachment of two chains of polymer molecules by bridges composed of molecular, in this case styrene, and primary chemical bonds. It produces a solid resin material that is impervious to most solvents, petroleum, and other chemicals found in the marine environment. Since styrene is consumed as part of this reaction, there is no need for removal of the diluents after the part is formed. 
However, due to the volatility of styrene, vapors from the application and curing process may pose an inhalation exposure hazard for workers near the process.

Humans exposed to styrene for short periods of time through inhalation may exhibit irritation of the eyes and mucous membranes, and gastrointestinal effects. ${ }^{1}$ Styrene inhalation over longer periods of time may cause central nervous system effects including headache, fatigue, weakness, and depression. Exposure may also damage peripheral nerves and cause changes to the kidneys and blood. Numerous studies have shown that styrene exposures were linked to central and peripheral neurologic, ${ }^{2,3,4}$ optic, ${ }^{5,6}$ and irritant $^{7}$ effects when occupational exposures to styrene vapors in air were greater than 50 parts per million (ppm). There is also evidence concerning the influence of occupational styrene exposure on sensory nerve conduction indicating that: (1) $5 \%$ to $10 \%$ reductions can occur after exposure at $100 \mathrm{ppm}$ or more; (2) reduced peripheral nerve conduction velocity and sensory amplitude can occur after styrene exposure at 50 to $100 \mathrm{ppm}$; (3) slowed reaction time appears to begin after exposures as low as $50 \mathrm{ppm}$; and, (4) statistically significant loss of color discrimination (dyschromatopsia) may occur. ${ }^{8}$ Some other health effects of low-level styrene exposure include ototoxicity in workers and experimental animals. Styrene exposure can cause permanent and progressive damage to the auditory system in rats even after exposure has ceased. ${ }^{9,10}$ Styrene has been shown to be a potent ototoxicant by itself, and can have a synergistic effect when presented together with noise or ethanol. ${ }^{11,12,13,14}$

The primary sources of environmental evaluation standards and guidelines for the workplace are: (1) the OSHA Permissible Exposure Limits (PEL); ${ }^{15}$ (2) The NIOSH Recommended Exposure Limits (REL) ${ }^{16}$ and, (3) the American Conference of Governmental Industrial Hygienists $\left(\mathrm{ACGIH}^{\circledR}\right)$ Threshold Limit Values $\left(\mathrm{TLV}^{\circledR}\right) .{ }^{19}$ Employers are mandated by law to follow the OSHA limits; however, employers are encouraged to follow the most protective criteria. The NIOSH REL for styrene is $50 \mathrm{ppm}$ for a 10-hour time-weighted average (TWA) (meaning the limit applies to the average exposure during a work day of up to 10 hours and a work week of up to 40 hours), with a 15-minute short-term exposure limit (STEL) of $100 \mathrm{ppm}$, limiting average exposures over any 15-minute period during the work day. ${ }^{17}$ These recommendations are based upon reported central nervous system effects and eye and respiratory irritation. The OSHA PEL for styrene is $100 \mathrm{ppm}$ for an 8-hour TWA exposure, with a ceiling limit of 200 ppm. ${ }^{18}$ The ceiling limit restricts exposures for any portion of the work day. The American Conference of Governmental Industrial Hygienists (ACGIH) revised its Threshold Limit Value (TLV ${ }^{\circledR}$ ) in 1997, and recommends styrene be controlled to 20 ppm for an 8-hour TWA exposure with a 40 ppm, 15-minute short-term exposure limit (STEL). ${ }^{19}$

In February 1996, Styrene Information and Research Center (SIRC) and three other styrene industry trade associations (American Composites Manufacturers Association, National Marine Manufactures Association, and the International Cast Polymer Association) entered into a precedent-setting arrangement with OSHA to voluntarily adhere to the 50-ppm level set by the 1989 update of the OSHA PEL (which was later vacated by the courts). The SIRC encouraged its members to continue to comply with 
the 50-ppm standard as an appropriate exposure level for styrene, regardless of its regulatory status. ${ }^{20}$

Exhaust ventilation, low styrene-content resin, non-atomizing spray equipment, and personal protective equipment have historically been recommended to limit styrene vapor exposures to workers. Recent developments in specific closed-molding technologies, however, may also provide protection by reducing process emissions of styrene, and, in turn, the concentration of styrene in the workers' breathing zones.

\section{Facility Description}

Grady-White's new facility, built a little less than a year ago, is located in Greenville, North Carolina. The manufacturing portion of the new building is split into three production bays. Bay 1 is located on the west side and houses hull lamination. Bay 2, located in the center, is the site of lamination of decks and liners. Bay 3, located on the south side of the facility, includes the closed-mold production of small parts in its southern section, and the open-molding production in its northern section. There are approximately 42 employees working in each bay. A plan view of the controlled-flow ventilation is shown in Figure 1. Outside air is pushed in from above across the lamination process and exhausted perpendicular to the supply region as seen in Figure 1 and 2 below. The arrows shown in Figure 1 and 2 depict the air movement across the hulls, decks, and liners (orange figures). After speaking with a Grady White representative, we found that when the ventilation system was set up it was spot checked using a ribboned pole for detection of airflow dead spots.

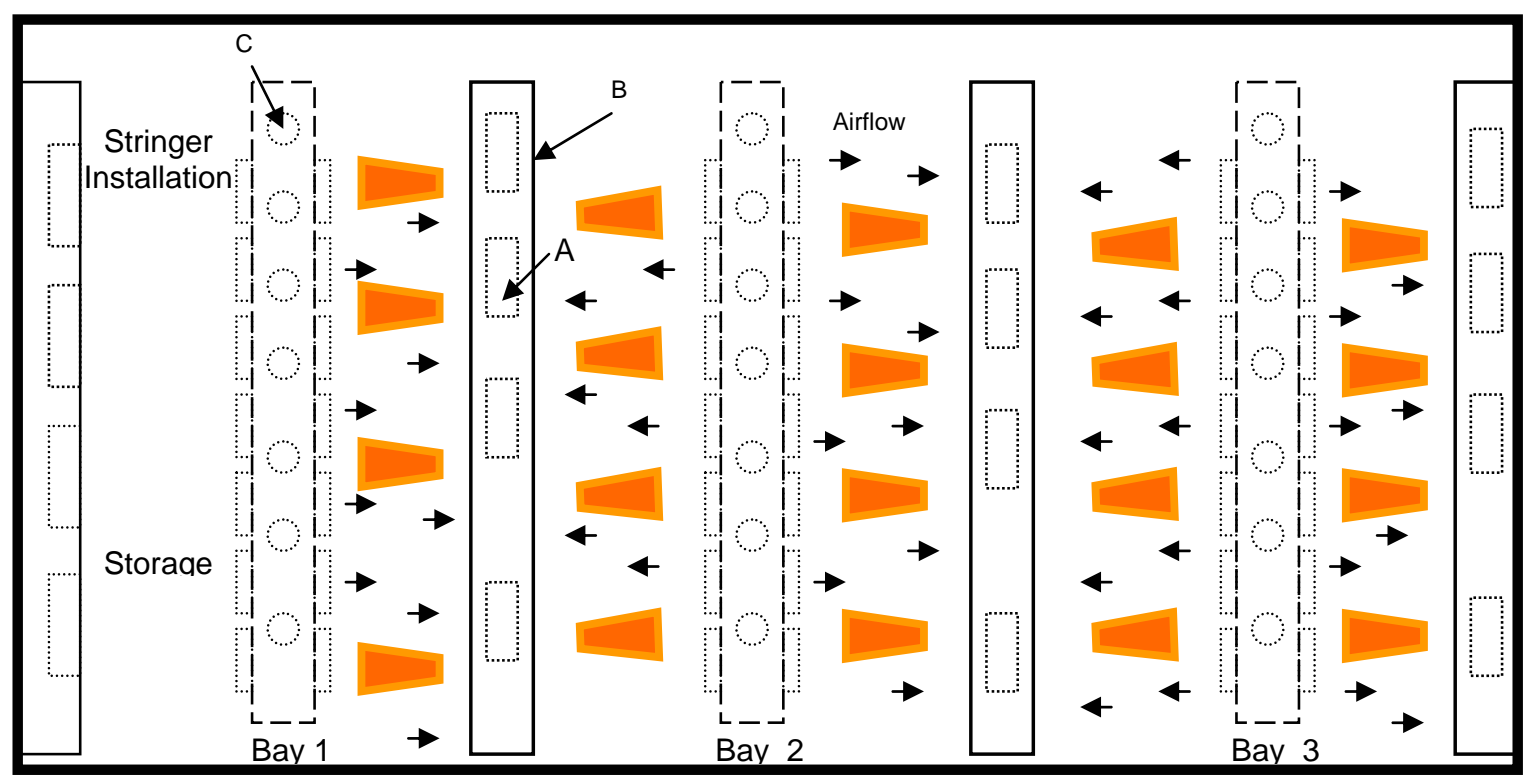

Figure 1: Plan View of Controlled-flow Ventilation installed by Frees Inc. (A) Vertical takeoffs (B) Filter surfaces (C) Vertical supply duct 


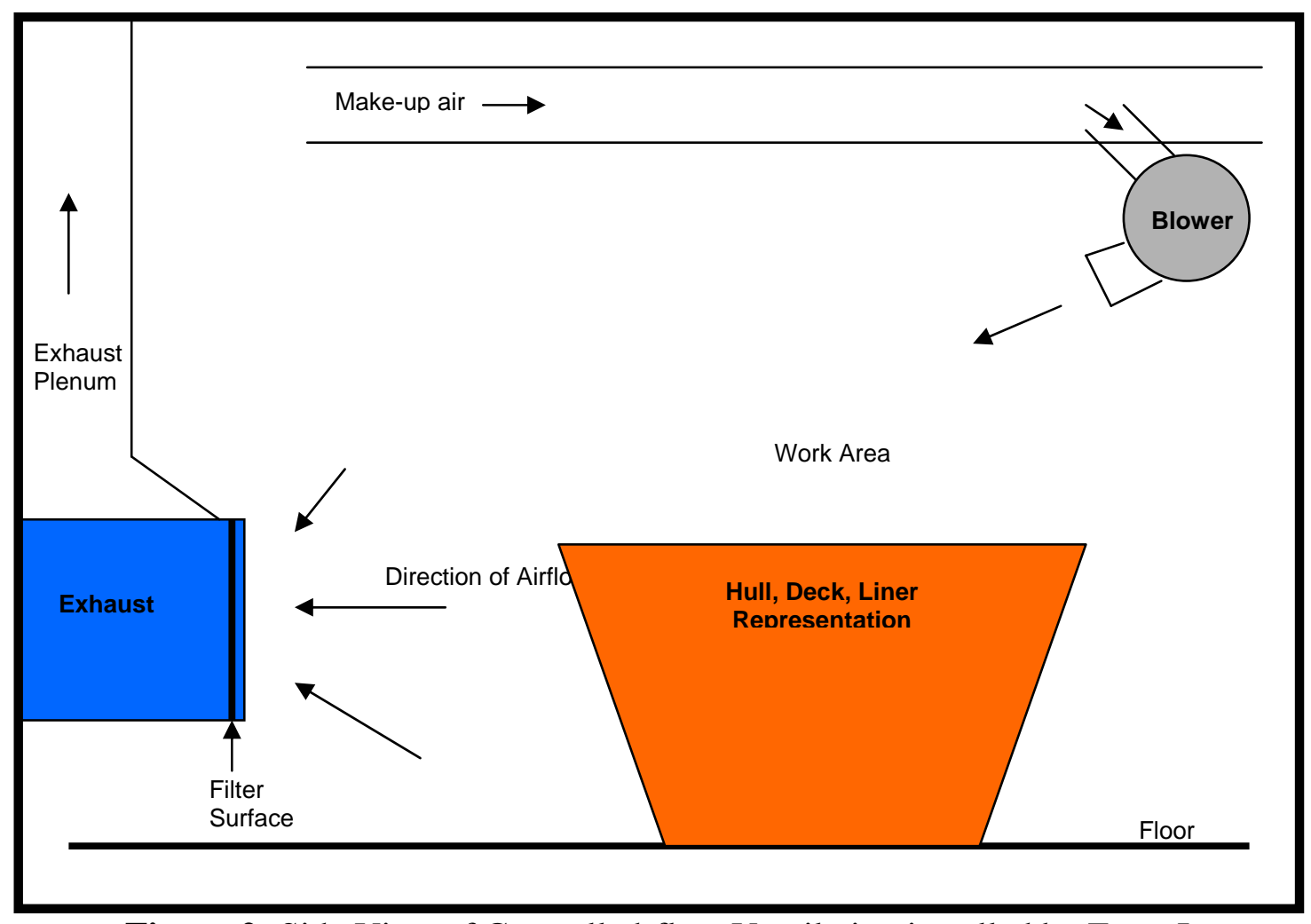

Figure 2: Side View of Controlled-flow Ventilation installed by Frees Inc.

\section{Process Description}

All of the parts that make up a Grady-White boat are designed using Computer-Aided Design (CAD) and Computer-Aided Manufacturing (CAM) systems. Frame designs were sent directly from the CAD system to the computer-controlled router for output. All boat designs are built in wood or urethane foam prior to production. The fiberglass molds used for production are made from these plugs.

Fiberglass boats are built from glass-fiber reinforcements laid in a mold and saturated with a polyester resin. The plastic resin hardens to form a rigid plastic part reinforced with the fiberglass. The gelcoating process starts when the mold is sprayed with a layer of gel coat, which is a pigmented polyester resin that hardens and becomes the smooth outside surface of the part. The lamination process begins with the placement of the precut fiberglass mats and is followed by the saturation of resin into the fiberglass mats. All fiberglass mats are hand-laid to provide a uniform laminate structure. The dry mat used is of the high porosity needed to allow resin penetration within the fiberglass structure of the mat during resin saturation (rolling process). Some hulls were rotated sideways which causes the air to pass through the hull area and then be pulled from behind into the exhaust system. The laminator worked standing approximately twelve inches from the mold. When stringers are glassed in, the hulls were horizontally oriented and the laminators working in these wore 3M organic vapor charcoal filter respirators. The personal breathing zone of each laminator was below the high ends of the boat. The orientation of the boat, when laminating, has to be horizontal due to the nature of the process and the detailed crevices in the hulls of the boat. 
A chopper gun (cuts fiberglass thread into small one inch pieces) is used for small parts and liners only. The hand-laid fiberglass mats and chopped fiberglass pieces are saturated with resin by a gunner using a MACT-compliant, low-flow, non-atomizing gun. The resin in each part is metered, measured and entered into the computer system so every part contains an optimal glass-to-resin ratio. The saturated resin was then handrolled and compressed by the rollers. The production resin used is MACT compliant and contains 33\% to 34\% styrene by weight. The laminators and gunners do not wear respirators. Once the fiberglass mats and resin are applied and the desired thickness has been achieved, a stringer system built of treated plywood is cut by a computerized router system then glassed into the hull while it is still in the mold. The preassembly of the stringer systems occurs in the southwest end of the building adjacent to the closed molding process. Hearing protection is worn by the employees constructing the stringers. There are approximately eight employees working in this bay. For floatation purposes, spray-in foam is applied between the stringers. According to Grady-White representatives, this provides a strong, light, and durable boat.

\section{Closed molding}

The cold-press pneumatic molding process is used only for small parts. The process consists of mixing together a resin, a catalyst (methyl ethyl ketone peroxide, or MEKP), and a filler, and pouring the mixture into a mold that has been sprayed with chopped fiberglass. The duty of the operator is to meter the resin mixture and pour the resin mixture into the mold. It is then placed into the pneumatic clamp machine and flattened. It takes about five minutes for the process to cure. Two molds are poured per process. A result occurring with this process is the amount of styrene waste that is emitted as the molds are flattened.

\section{Resin Storage Area}

There are two 6,000-gallon resin tanks stored outside of the facility. One full tank of resin is used every 4 or 5 days. All of the tanks are jacketed to assure a storage temperature of 75-80 degrees Fahrenheit. The temperature is controlled by water through a shell-and-tube heat exchanger.

\section{$\underline{\text { Results }}$}

Styrene detector tubes were used to estimate concentrations of styrene vapor in the air in areas where NIOSH researchers observed a high use of styrene-containing products. The range of detection of the tubes used was 10 to $250 \mathrm{ppm}$. Results are given in Table 1. 
Table 1: Results of Styrene Detector Tube Samples taken throughout the Grady White Facility in Greenville, North Carolina

\begin{tabular}{|l|l|c|}
\hline Building Area & Description & Approximate Concentration [ppm] \\
\hline Bay 2 & near lamination line & $15-20$ \\
\hline Bay 3 south end & near resin tanks & 10 \\
\hline Bay 3 south end & closed molding near operator & 15 \\
\hline Bay 1 & $\begin{array}{l}\text { Stringer glass-in (hulls rotated side- } \\
\text { ways) }\end{array}$ & \multicolumn{1}{|c|}{40} \\
\hline & $\begin{array}{l}\text { Stringer glass-in (hulls rotated } \\
\text { horizontally), sample taken above } \\
\text { the edge of the boat }\end{array}$ & 250 \\
\hline
\end{tabular}

\section{Preliminary Conclusions and Recommendations}

The highest concentration detected in Bay 1 (stringer glass-in) was approximately 250 ppm. The personal breathing zone of each laminator was below the high ends of the boat. It is believed that the high concentrations were due to the orientation of the boats and the entrapped air contained in the boat. The orientation of the boat has to be horizontal due to the nature of the process and the detailed crevices that are in the hulls of the boat. It is recommended that longer-handled rolling instruments be considered in order to have the workers' breathing zones further away from the surface of the resin. The continued use of the organic-vapor charcoal-filter respirators is highly recommended especially for those workers involved in the rolling process of hulls oriented horizontally. Styrene emissions seemed to be reasonably well controlled in the remainder of the plant, outside of this area. The ventilation systems installed seem to be working properly. A further investigation of this plant still needs to be discussed with NIOSH researchers. 


\section{REFERENCES}

${ }^{1}$ Environmental Protection Agency (EPA): National Emission Standards for Hazardous Air Pollutants for Boat Manufacturing; Proposed Rule, Part II. 40 CRF Part 63, July 14,2000 .

${ }^{2}$ Mutti A, Mazzucchi A, Rustichelli P, Frigeri G, Arfini G, Franchini I: Exposureeffect and exposure-response relationships between occupational exposure to styrene and neuropsychological functions. Am J Ind Med. 5:275-286 (1984).

${ }^{3}$ Fung F. Clark RF: Styrene-induced peripheral neuropathy. Journal of Toxicology Clinical Toxicology. 37(1):91-7 (1999).

${ }^{4}$ Tsai SY. Chen JD. Neurobehavioral effects of occupational exposure to low-level styrene. Neurotoxicology \& Teratology. 18(4):463-9, (1996).

${ }^{5}$ Gong, Y. Y., R. Kishi, et al: Relation between colour vision loss and occupational styrene exposure level. Occupational \& Environmental Medicine 59(12): 824-9 (2002).

${ }^{6}$ Triebig, G., T. Stark, et al: Intervention study on acquired color vision deficiencies in styrene-exposed workers. Journal of Occupational \& Environmental Medicine 43(5): 494-500 (2001).

${ }^{7}$ Minamoto K. Nagano M. Inaoka T. Futatsuka M: Occupational dermatoses among fibreglass-reinforced plastics factory workers. Contact Dermatitis. 46(6):339-47, (2002).

${ }^{8}$ American Conference of Governmental Industrial Hygienists (ACGIH):

Documentation of Threshold Limit Values and Biological Exposure Indices: TLV for Styrene. American Conference of Governmental Industrial Hygienists. Cincinnati, $\mathrm{OH}$, (2001).

${ }^{9}$ Campo P, Lataye R, Loquet G, Bonnet P: Styrene-induced hearing loss: a membrane insult. Hearing Research 154(1-2):170-80 (2001).

${ }^{10}$ Lataye R. Campo P. Pouyatos B. Cossec B. Blachere V. Morel G: Solvent ototoxicity in the rat and guinea pig. Neurotoxicology \& Teratology. 25(1):39-50 (2003).

${ }^{11}$ Morata, T. C., A. C. Johnson, et al: "Audiometric findings in workers exposed to low levels of styrene and noise." Journal of Occupational \& Environmental Medicine 44(9): 806-14 (2002).

${ }^{12}$ Sliwinska-Kowalska M, Zamyslowska-Smytke E, Szymczak W, Kotylo P, Fiszer M, Wesolowski W, Pawlaczyk-Luszczynska M: Ototoxic effects of occupational exposure to styrene and co-exposure to styrene and noise. Journal of Occupational and Environmental Medicine 45 (1): 15-24 (2003). 
${ }^{13}$ Makitie AA. Pirvola U. Pyykko I. Sakakibara H. Riihimaki V. Ylikoski J: The ototoxic interaction of styrene and noise. Hearing Research. 179(1-2):9-20 (2003).

${ }^{14}$ Lataye R. Campo P. Loquet G: Combined effects of noise and styrene exposure on hearing function in the rat. Hearing Research. 139(1-2):86-96 (2000).

${ }^{15}$ Occupational Safety and Health Administration. Code of Federal Regulations. 29 CFR 1910. “Occupational Safety and Health Standards.” U.S. Government Printing Office, Office of the Federal Register. Washington, D.C., (2002)

${ }^{16}$ National Institute for Occupational Safety and Health. "Recommendations for occupational safety and health: compendium of policy documents and statements." U.S. Department of Health and Human Services, Public Health Service, Centers for Disease Control and Prevention, National Institute for Occupational Safety and Health, DHHS (NIOSH) Publication No. 92-100 (1992)

${ }^{17}$ National Institute for Occupational Safety and Health (NIOSH): NOISH Pocket Guide to Chemical Hazards and Other Databases - REL for Styrene. DHHS (NIOSH) Pub. No. 2004-103 (2004).

${ }^{18}$ Occupational Safety and Health Administration (OSHA): OSHA National News Release. U.S. Department of Labor Office of Public Affairs: News Release USDL, 96-77: March 1, 1996.

${ }^{19}$ American Conference of Governmental Industrial Hygienists (ACGIH): TLVs ${ }^{\circledR}$ and BEIs ${ }^{\circledR}$ Threshold Limit Values for Chemical Substances and Physical Agents \& Biological Exposure Indices. American Conference of Governmental Industrial Hygienists. Cincinnati, OH, (2004).

${ }^{20}$ Office of Public Affairs (Washington D.C.) [1996]. OSHA announces that styrene industry has adopted voluntary compliance program to improve worker protection. News Release, 01 March 1996. Washington, DC.

http://www.acmanet.org/ga/osha_styrene_agreement_docs_1996.pdf. 